\title{
Maternal Behavior Their Adjustments and Implicated Factors
}

\author{
Esther Pérez-Torrero*, Lorena Rubio-Navarro \\ División de Investigación y Posgrado, Facultad de Ingeniería, Universidad Autónoma de Querétaro, \\ Querétaro, Mexico \\ Email: *esther.torrero@uaq.mx, dl.rubio.navarro@gmail.com
}

Received 14 January 2015; accepted 24 February 2015; published 26 February 2015

Academic Editor: Juan J. Canales, University of Leicester, UK

Copyright (C) 2015 by authors and Scientific Research Publishing Inc.

This work is licensed under the Creative Commons Attribution International License (CC BY).

http://creativecommons.org/licenses/by/4.0/

c) (i) Open Access

\section{Abstract}

The maternal behavior in mammals is one of the most stable and highly conserved motivated species-specific behaviors and crucial for reproductive functions. During maternal behavior nursing and feeding are associated factors with survival of mammalian offspring, mammals nurse their newborn in a wide diversity in the behavioral. In the mother relationship the suckling is the behavioral patterns that identified and unified mammals and showed several selected evolutionary conserved behavior. The milk is an important reward for the pups, it ensure the surviving. The quality of maternal behavior is transmitted between generations; the inadequate maternal care has harmful effects in the adulthood individual. The specific maternal pattern modalities differ greatly between species; the human bonding has underlying biological mechanisms similar in mammals. Maternal brain is modified in order to prepare the mother-pup relationship, being crucial for the adequate behavioral display in the mother-pup relationship. A bulk of surrounding factor such as sensorial stimulus, temperature, ultrasonic communication, and reinforcing stimulus determines the quality of the nursing and care of the progeny. Mother care and nursing quality have long lasting effects in adulthood, determining cognitive and behavioral development and some specific psychiatric and psychological condition in human populations.

\section{Keywords}

Maternal Behavior, Lactation, Mother-Pup Relationship, Offspring, Brain, Suckling

\section{Introduction}

Mother-pup relationship, showed in rodents to humans, is common in mammals and takes place through evolu-

Corresponding author. 
tion; it is exceptional to the females allowing prenatal resources for survive of their offspring at birth. Reciprocal empathy between the mother and pup is mainly reached by the olfactory signals. The mutual display of the mother-young interaction is stimulated by several pup stimuli such as tactile or auditory stimuli, which are important for supporting the mother-pup link. Rodent pups emit ultrasonic vocalization, oxytocin plays a crucial role in the establishment of the mother-pup bond, and several hormonal levels are also implicated. Disruption of mother-infant bonding greatly affects neurobehavioral development in infants, even if weaning occurs in the later lactating period.

Mammalian newborn show a stereotyped and rigid behavior (crying, squealing, urination and so forth). The reciprocal exposition of maternal behaviors and newborn signaling promotes physiological and immunological resistance, physical maturation, social and emotional development in the newborn. Mother-pup interactions increase the probability that the young will survive and, ensure the successful reproductive functions [1]. Maternal behavior patterns show plastic mechanisms, which depend on brain structures functions substantially influenced by experience acquired in a previous parturitions [2]. Mother-infant separation produces a stressed condition that modifies physiological and behavioral function in the offspring [3]. The pup responses showed as changes in cardiovascular function, temperature, locomotors behavior, developmental delays, and immune depression following of prolonged separation [4].

The development process offer the capacity in both mother and neonate to express and modify maternal behavior patterns in adulthood may depend on mechanisms that were themselves activated and later influenced by early experiences. The central role of maternal care in early life is also knows in rodent studies, newborn rodents are incapable of body temperature maintenance, are dependent for their survival from the initiation of a specific pattern of maternal behaviors [5] [6].

Maternal behavior included the activities that realize the mother oriented to the pup care and patterns that characterize are nest building, cleans the pups and carries one-by-one to the nest in her mouth, grouping pup together, crouching, licking specially their anogenital regions (Figure 1), intruder aggression, nipple attachment and eventually adopt a nursing posture over pups and nursing [1] [5] [7]-[9]. During the first week, the mother give the milk to the pups and is the only source of nutriments and liquid, the milk is a good source of macronutrients and micronutrients, but contain other active constituents [10]. The constituents and amount of milk varies in the different species and may reflect the adaptive strategies to environmental conditions. During lactation period the milk have the principal nutrimental components, fat, protein, carbohydrates and ash elements. Exists some differences between colostrum and mature milk, in colostrum the protein content increase and decrease the

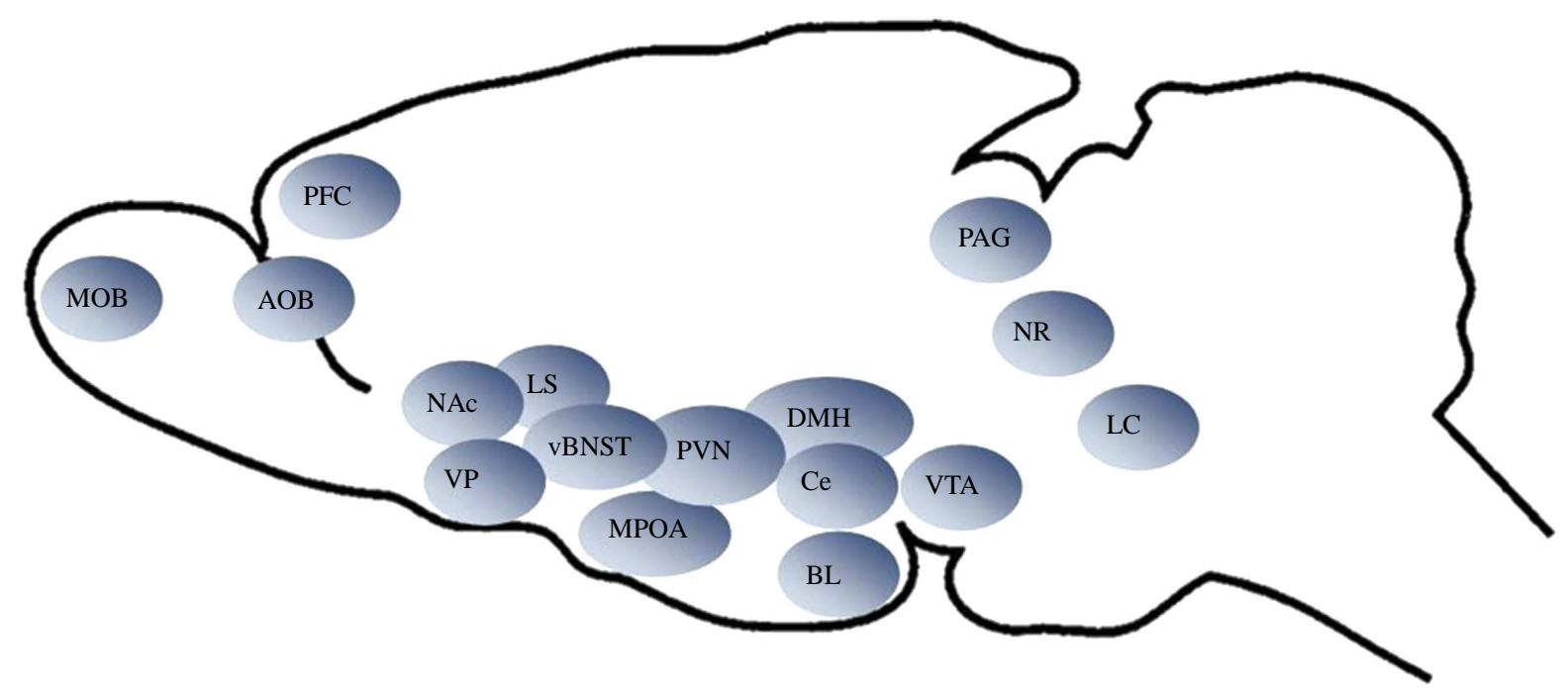

Figure 1. Brain nucleus involved in the regulation of maternal behavior, as supported by direct in rat. MOB, main olfactory buld; PFC, prefrontal cortex; NAc, nucleus accumbens; VP, ventral pallidum; Vbnst, bed nucleus of stria terminalis, ventral part; MPOA, medial preoptic area; PVNm, paraventricular nucleus; BL, basolateral amygdala; Ce, central amygdala; VTA, ventral tegmental area; PAG, periaqueductal gray; NR, raphe nucleus; LC, locus coeruleus; AOB, accessory olfactory buld; LS, lateral septum; PVNp, paraventricular nucleus; DMH, dorsomedial hypothalamic nucleus; VMH, ventromedial hypothalamic nucleus. 
content of carbohydrates, the fat do not have variation during the lactation period. In colostrum, the lacteal fluid contains antibodies of immunoglobulin, these proteins are complete and biologically active and growth factors that promote pup developmental [11] [12]. In the other hand, the altricial mammal's species depend from the mother rat to provide warm and protection of predators, the onset of maternal aggression in rodents seems to require both the hormonal changes occurring at the end of pregnancy and the presence of the pups [13]. From our analysis we observed that lactating mother spend the most of time to the pup care mainly the first week and gradually decreases, while the young become independent and the mother spend less time in nurturing behavior [14].

The hormone oxytocin is implicated on survival and reproductive activities during vertebrate evolution. In humans oxytocin participate in the physiological changes that characterize the neonatal period such as birth and maternal-relationship in the postpartum period. The oxytocin participate in the physically development of the individual. The findings animal models research showed that released oxytocin from hypothalamic nuclei is fundamental facet of maternal behavioral system in the mother-pup relationships. Differences in limbic circuitry and connections with central oxytocin and dopamine systems ultimately determine individual differences in maternal behavior in female rodents. Findings showed individual differences when oxytocin receptor was blockade [15]. In the case of human maternal behaviors are far more complex, because components such as cognitive flexibility, attentional control, memory, mother's recognition, and feelings expressions characterized human motherinfant bonding. The oxytocin is crucial for the individual existence due to their dependence on social behavior and cognitive superior activities [16].

\section{Neuronal Network Involved in Maternal Behavior}

The neuronal network implicated in adjustment of the maternal behavior includes the medial preoptic area (MPOA) of the hypothalamus, the ventral region of the bed nucleus of the stria terminalis (vBNST), the lateral septum (LS) [9] [17]-[22]. In the other hand several structures of the central nervous system (CNS) mediate the sensory components of maternal behavior (parietal cortex and olfactory bulbs) being activated when the parents sniffs, licks, mouth and crouches over the pups [3] [23]-[25]. The vomeronasal and primary olfactory systems has identified as brain areas that mediate avoidance behavior in virgin females rats exposed to the odor signals of pups [2]. Integration of input from both olfactory systems occurs within the medial amygdale (MA), previously associated with emotion, fear, and anxiety [19]. Data suggested that novel olfactory stimuli from pup activate fear-inducing mechanisms in the amygdala, and inhibit maternal behavior in virgin females. On opposition, lesions of the MA in nuliparous rats encourage maternal responsiveness [26]. A role for amygdaloidal nuclei in the expression and maintenance of maternal behavior has demonstrated (Figure 1). Findings suggest that the MPOA and vBNST as likely areas were the MA projects to restrain maternal behavior. Connections with another region such as the anterior hypothalamic nucleus (AHN), ventral medial nucleus (VMN), LS, and dorsal premamilary nucleus (PMN) may also be involved in the neural circuitry through which olfactory input initially restrain maternal responsiveness [20].

In the other hand experimental lesion in the pathways [21], at lateral MPOA, vBNST connection or unilateral axon excitotoxic amino acid lesion of the MPOA/vBNST would disrupt Fos expression during maternal behavior in the following regions LS, nucleus accumbens (NA), ventral tegmental area (VTA) or periaqueductal gray (PAG) key regions in maternal behavior. The parietal cortex also appears be implicated in maternal experience; the effects are reliable with evidence that this sensory receptive area display plastic mechanisms and re-organizes in relation to the previous parturitions in adult rodents [5]. A mixture function for the MPOA, the limbic system, the olfactory and somatosensory systems in the beginning and preservation of maternal behavior is consistent with learning, memory and emotive functions of these nervous structures [5] [24].

Neuroendocrine system plays a key role in the initiation of maternal behavior following birth, high oxytocin receptors expression in key brain regions, such as MPOA, VTA and nucleus accumbens is evident [25] [27]. Dopamine depend on the release of the oxytocin the source of dopamine facilitating maternal behavior are the VTA and substantia nigra, the destroy of monoamine cells block maternal behaviors because this areas are implicated in licking, grooming, bonding and reward, motivations and reinforcement [22] [28]. The initiation and maintenance of maternal behavior involves a specific neural pathway due to the brain regions involved in their adjustment (Figure 1). With pregnancy or with repeated exposure to pups, structural and molecular changes occur, in specific limbic hypothalamic, and midbrain regions that reflect the adapted mechanisms to respond to the 
several homeostatic demands associated with maternal care. Maternal behavior displayed most speedily when the parturition hormones are present although, both signal pups and hormonal environment act for integrate the mother-pup relation. However, the mother postpartum experience can also affect when the effects of parturition hormones are minimal. In species that recognize their own pups from others young (sheep mothers, ewes), mothers quickly learn to identify their own infants based on their odor signals. In species, that does not show selectivity such as rats, the early postpartum experiences with the pups care aid to maintain maternal behavior during subsequent nursing period. Learning processes are involved in mother experience and recognition of individual young; the establishment mechanisms are different from those that regulate the previous pup expositions [29].

Several structural changes in the pregnant rat, in the outermost layer in the cortex are most complex, this area receives and process sensory information and control voluntary movements, in the MPOA the volume of cell bodies in pregnant rats increase and the length and number of dendrites, related to the attention and motivation necessary to maternal behavior establishment. More concentrations of spine in CA1 of the hippocampus related to the substrate that supports the spatial memory learning in the mother rat [1].

Behavior patterns show only plastic mechanisms, which depend on brain structures and function that substantially influenced by experience acquired in a previous parturitions [2]. The development process of the capacity in both mother and neonate to express and modify maternal behavior patterns in adulthood may depend on mechanisms themselves activated and later influenced by early experiences. The mother-pup interaction alters basic mechanisms of behavioral expressions in both. Mother responses partially determine the neurobiological changes in the young [3] [4] [8].

In humans during prenatal period ovaries and placenta produce substances such as estrogen and progesterone. Other brain regions have glandular activity, so for example the hypothalamus secret oxytocin and pituitary gland secrete prolactin, which stimulates uterus contractions and mammary glands respectively. Studies carried out using animal modes showed that these reproductive hormones interfere with the physiological and morphological modifications in brain structures involved in the maternal responses. Studies carried out by several methods [15] [16] showed the activation of specific structures associated to human maternal behavior (Table 1).

\section{Nursing and Care Pattern}

Mammals nurse their pups in a variety of environment and circumstances and display huge diversity in the pattern of their nursing behavior (Figure 2 and Table 2). Attraction to the nipples is follow by the development of nipple-preferences associated to the selection of the best position nipple based on tactile and thermal characteristics of the mother ventral surface. There is also notorious variation in the frequency and of nursing among the different species [30].

Marsupials are particularly interesting that they show concurrent but asynchronous lactation in their mammary glands, whereby one pup continuously attached to the nipple while the other is suckling intermittently. Laboratory rats nurse their young for a total of 12 to 18 hours per day with frequent periods of nursing lasting 20 to 30 minutes. The other extreme are rabbits, which feed their offspring only once a day for just 4 to 5 minutes, and free shrews, which nurse every 2 days are species such as the domestic pig, which nurses approximately once per hour for 10-minte periods. In the horse suckling occurs for period from 1 to 20 minutes every 20 minutes. The bottle-nursed whale and the dolphin feed their calves at half-hourly intervals. Women nurse approximately every 4 hours, with variations in different cultures such as in the Kung tribe of African, the baby way suckles every few minutes per day [31].

Based on the findings that maternal behavior in virgins but not in parturient rats is suppress in part by olfactory stimuli from pups [32] [33]. The offspring gradually spend less time suckling and eventually cease it completely. The acceptance that suckling is an ontogenetic adaptation and not merely a precursor for adult intake behavior is well supported [34] [35]. However, the mechanisms that underlie this transition from complete dependence on the mother to autonomous feeding are not understood. In case of the rats on Day 25 attachments are dependent on recent suckling experience [36], although pups prefer first nutritive to nonnutritive suckling at 17 day [37]. Suckling behavior does not differ between 25-day-old rat pups that were housed with a dam whose nipples were ligated and pups housed with an intact dam [38] suggesting that milk contributes slight to the maintenance of suckling before Day 25.

Housing juvenile rats with other dams and their pre-weaning litters can prolong weaning period. The 
Table 1. Brain structure involved of human maternal behavior adjustments.

\begin{tabular}{|c|c|}
\hline Brain Structure & Adjusted Action \\
\hline Dorsolateral prefrontal cortex & $\begin{array}{l}\text { Superior control of cognition } \\
\text { Emotional behaviors } \\
\text { Executive function } \\
\text { Personality } \\
\text { Emotion }\end{array}$ \\
\hline Obitofrontal cortex & $\begin{array}{l}\text { Reward stimulus } \\
\text { Impulsivity } \\
\text { Response inhibition } \\
\text { Visceral responses } \\
\text { Emotion }\end{array}$ \\
\hline Periacueductal cingulate cortex & $\begin{array}{l}\text { Affective behavior } \\
\text { Personality control } \\
\text { Integrating internal signals (anxiety and depression) }\end{array}$ \\
\hline Subgenual anterior cingulate cortex & $\begin{array}{l}\text { Emotion } \\
\text { Socialization } \\
\text { Anxiety } \\
\text { Depression } \\
\text { Associative learning behaviors }\end{array}$ \\
\hline Hypothalamus & $\begin{array}{l}\text { Integrative functions: } \\
\text { Neuroendocrine regulation } \\
\text { Vital physiological signals } \\
\text { Neuroactive substances activity } \\
\text { Reproductive behaviors } \\
\text { Emotive behaviors }\end{array}$ \\
\hline Nucleus accumbens & $\begin{array}{l}\text { Motivated behavior (emotion and reward) } \\
\text { Addictions } \\
\text { Depression }\end{array}$ \\
\hline Amygdala & $\begin{array}{l}\text { Sensitive perception } \\
\text { Integrate affective behaviors } \\
\text { Emotions } \\
\text { Anxiety } \\
\text { Stress } \\
\text { Autonomics responses }\end{array}$ \\
\hline
\end{tabular}

(a)
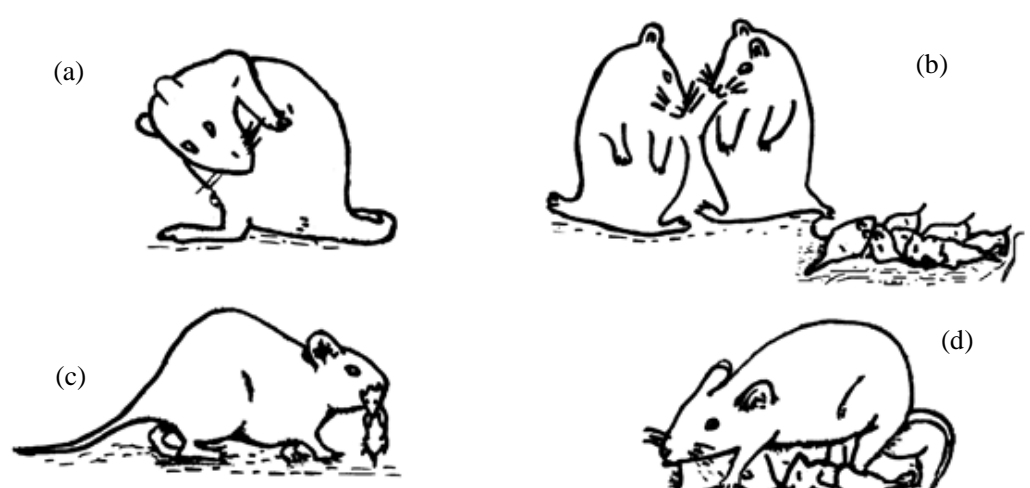
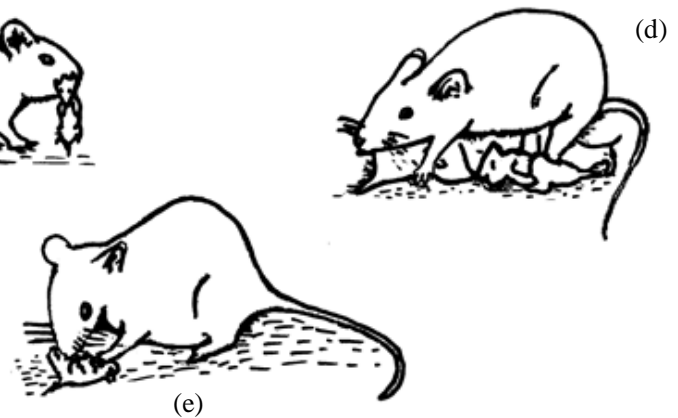

(e)

Figure 2. The different components of maternal pattern, displayed during lactation period in rat. (a) Grooming; (b) Aggression; (c) Carried; (d) Nursing posture; (e) Anogenital licking. 
Table 2. Nursing and care pattern behavior that characterize mother-pup relationship in rat [36]-[38].

\begin{tabular}{ll}
\hline \multirow{4}{*}{ Maternal activities } & Nest building \\
& Placentophagia \\
& Consumption of amniotic fluid \\
Stimulation of newborn (anogenital licking) & Non-nutritive contact \\
& Defensive aggression \\
& Retrieval (latency and retrieval number) \\
& Grouping (latency) \\
Non-nutritive contact (duration) \\
Nursing contact (latency to an nutritive episode) \\
Licking and grooming pups \\
Nursing posture/crouching \\
Providing warmth and safety/nest building \\
Maternal aggression \\
Increased food consumption (active) \\
Self-related behaviors (grooming and eating) \\
Ron maternal self-directed and motor activities & Exploratory motor activities (horizontal activities) \\
& Rearing \\
\hline
\end{tabular}

opportunities to attach as well as the continued availability of milk become increasingly important in the maintenance of suckling as the pups mature [39]. These results suggest that the fluid with distinct oral hedonic properties but lacking postingestive value, such as saccharin are implicated in duration of weaning period [40] [41].

The motor pattern of the newborn rats is characterize for simplest and stereotyped movements and can be consider like precursors of adult behavior but in the adult new types of movements is incorporate to the patterns of behavior; the new movements are associated with changes in the central and peripheral nervous systems and musculature morphology [42] [43].

\section{Nitric Oxide and Maternal Behavior}

The gas nitric oxide (NO) is produced by some subtypes of nitric oxide synthase (NOS), the enzyme NOS is on three related isoforms. The three isoforms are found in the brain blood vessels named endothelial (eNOS), the inducible isoform (iNOS) is confined to glial cells, while the neuronal (nNOS) is synthesized primarily by neuros. Labors to recognize the function of NO in brain, findings showed that altered aggressive behavior when nNOS activity was inhibited [44]-[46]. The NO activity was observed in the formation at the synapse, related to the neurotransmitter activities of glutamate. When glutamate fixes to a N-methyl-D-aspartate (NMDA) receptor the gas NO is released into the postsynaptic neuron, when glutamate binds to a NMDA receptor causes channels opening in the membrane and permit calcium ions $\left(\mathrm{Ca}^{2+}\right)$ from the fluid in the synapse space to enter the postsynaptic neuron and binds to calmodulin, which stimulates NOS to convert arginine (Arg) into NO and citruline (Figure 3). In addition has demonstrated that NO is likely influence neurons over a large volume, it is possible due to is appropriate quantity and because is soluble in both in water and lipid [47]. The aggressive behavior oriented to protect the progeny increase with a specific nNOS inhibitor, 7-nitroindazole, demonstrated the crucial function of NO in the maternal aggressive behavior adjustment [46] [47].

Maternal aggression oriented to an intruder in the homing cage also is included in maternal behavior repertoire, such as nursing, pup retrieval, grooming and licking. Although, less is known about the possible neural basis of maternal aggression toward intruders, some studies indicates that the biogenic amine norepinephrine the full repertoire of many murine maternal behaviors, such as pup retrieval, around the time of parturition. Nitric oxide (NO) is present at the time of parturition in rats [48] and to the formation of olfactory memories in lactating sheep [49]. In the study about the NO implications in maternal behavior [50] demonstrated an increase in citruline-IR in MPOA, SCN and Supra ventricular regions of the hypothalamus, but in other areas is associated with maternal aggression. In the cat, electrical stimulation of the hypothalamus dorsal and just lateral to the third ventricle elicits defensive rage, which is equivalent to the maternal aggression.

The beginning of maternal aggressive behavior in rodents seems to require both fluctuations at the end of 


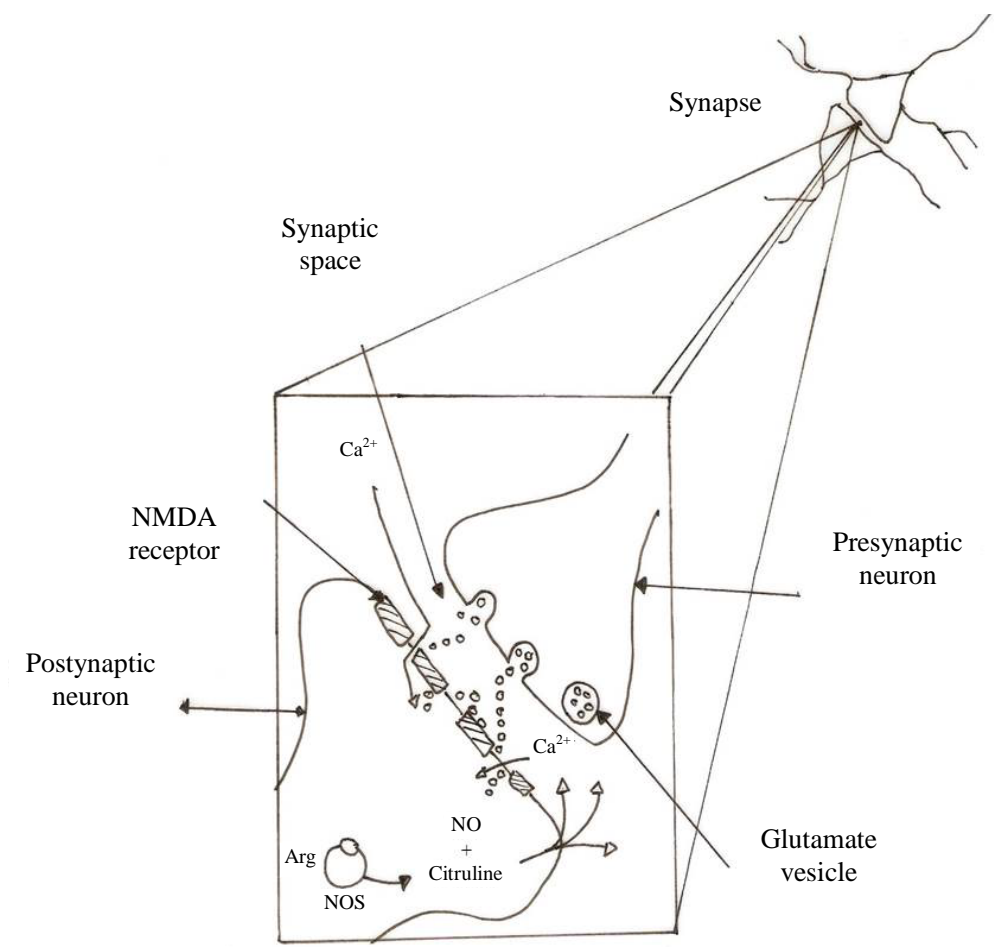

Figure 3. The NO activity at the synapse, implicated as a neurotransmitter activities of glutamate at synapses.

pregnancy and the presence of the pups. The prolactin participates in to the emergence of postpartum aggression in mice and hamster, in rats, gonadal hormones influence de onset of maternal aggression. In non-pregnant ovariectomized rats treated with estradiol and progesterone such as lactating female rats, the presence of the pups and their somatosensory stimulation on the mother are necessary to induce aggressive behavior. Number of pups also increases the frequency of mother attack to the intruder. In mice, suckling can induce aggression in virgin females, in rats, sucking alone do not provide sufficient stimulation to elicit maternal aggression. During the first 10 days after birth female rats vigorously attack intruders in the nest site, and thereafter decline even though lactation continues. Natural decline of maternal aggression after 10 days postpartum, previous study showed no relationship between the physical development and decrease of aggressiveness [51].

\section{Sensory Stimuli and Environment Factors Involved in Mother-Pups Interaction}

Initial maternal learning it depends mainly on somatosensory and chemosensory modalities, the anosmic mothers cannot smell pups, unable of receive somatosensory signals of the belly and mouth regions [52]. The maternal and nest environment provide a rich learning stimulus for the developing young. Pups also acquire learning during the pre-weaning period that affects their adjustment to the mother and later on to their progeny. Rat pups develop a recognition behavior to the chemosensory characteristics from the mother ventrum and attaches to the nipples based on previous intrauterine olfactory learning of the amniotic fluid [53].

Recognition and preference of maternal odor, depends of central processing of olfactory information by the limbic structures. Establishment of the association between licking and maternal odorant signals dependent of licking induced activation on the midbrain nucleus, the locus coeruleus (LC), whose axons determinates in the olfactory bulbs and release the norepinephrine. Processing of the olfactory bulb inputs by amygdale mechanisms determines the importance of olfactory stimuli and the nature of affective responses to them [54]. The relationship of rat pups to approach and attach to the mothers is strong dependent on the experience of olfactory and limbic mechanisms that mediate attraction and recognition to the mother and her environment [2].

Stimulus from the pup produce effects on the nervous system of the mother virgin rats can be induced to display maternal behavior if are exposed repeatedly exposure to young rats on five and seven age-days [55]. However, maternal behavior showed better when the parturition hormones are present. Hormonal influences are as- 
sociated with the odor perception, feeling and sound with motor responses involved in picking up and moving pups and adopting a crouch posture over pups.

The parturition hormonal fluctuations and exposure to pups, the mothers become habituated to their odors and other novel aspects that would usually activate fear and withdrawal. Mother sheep learn the individual odors from lambs; rodent mothers do not develop individual recognition. They respond to their own and other litters of the same age in the same way. Parturition hormones enhance the attractiveness of pups and their odors and facilitate maternal learning [56] [57].

The integrity and plasticity of maternal learning/memory varies with frequency, duration, exposure, and the interval between exposure and test. Initial maternal learning depends primarily on somatosensory and chemosensory modalities. The anosmic mother cannot smell pups and are unable to acquire somatosensory stimulation of the belly and mouth region such as due to application of anesthetic onto or into these regions, the mother do not licked and retrieve the pups. Maternal olfactory and somatosensory processing is necessary for pups to acquire reinforcing value, and for the mother to retain responsiveness to pups over long period when dams separated from their liter 4 horas during 14 days [58]-[60].

In mammals the maternal and litter context in the nest provide a rich learning environment for the developing young. Mothers and offspring both learn about their offspring gain experiences during the pre-weaning period. Attraction is mainly due to the nipples preferences, i.e. kittens develop preference for a special nipple in the mother belly. This preference established by experience; the ideal nipple also is associated with tactile thermal characteristics of nipple localization [61]. In rats food preferences first defined on mother diet and odors and then to food particle remaining in the mother's mouth and on her fur and finally followed the mother to the food place. Discrimination by weaned animals of nutritive and nutritionally deficient diets is influence by learning processes [62].

Recognition of the mother odors by pups occurs associated with the licking of the pups by the mother. The tendency of rat pups to approach and attach to the mother is deeply dependent on the experiential effects on olfactory and limbic mechanism $\mathrm{s}$ that mediate attraction to and recognition of the mother and surroundings. Concurrent early olfactory experiences (mother's odors) and somatosensory experiences (such as nursing, licked) also appear to have long-term effects on the infants as they grow. Infant's rats who receive more touch and licking stimulation from the mother in the nest show a higher level of pup licking as juvenile and as adults when presented with new born pups, by comparison to little stimulated infants [63]. Learning and plasticity in the mother-young relationships play a critical role in promoting adaptive fitness in mammalian species, establishing exactly how the neurobiological changes produced by early experiences might persistently alter the neurobiological mechanisms providing the establishment for later maternal learning and plasticity changes [64].

\section{Temperature}

The pattern of mother-young contact in Norway rats is regulating in part by thermal factors. Huddling with the young leads to an acute rise of the females' body temperature, by terminating the contact, the dam is able to relieve her hyperthermia. It is the rate of rise, which is important when more rapid occurs the rise more quickly the dam terminates contact. When given the opportunity, dams will establish a nest site in a greatly warmer place available [65] [66].

The dams will construct a nest it given appropriate materials [67], naturally, will select a nest site, which is warmer than laboratory room temperature. One function of the nest is isolative; in a $16^{\circ} \mathrm{C}$ setting, pup temperature maintained at approximately $34^{\circ} \mathrm{C}$. Further dams modify the structure of the nest in response to changes in temperature, as the pups grow up [68]. Advantages in the selection of the most warm nest site may related with pups and dam, probably expend less energy on heat production, with the result that the dam probably does not need to spend as much time huddling with the pups warm. The dam may also to save time in delivering milk, because have been demonstrated that milk release is quicker in warm ambient temperature [69]. The combined savings in time spent with the pups, then, could be use engaging in foraging if food were scarce or simply resting if food were copious [70]. Both the durations of individual nest bouts, and thus total contact time, were decrease when nesting on a warm surface, the time over which they tested was only $24 \mathrm{~h}$.

Another study of rats demonstrated that on Day 21 postpartum, pups that had been reared in a nest constructed of newspaper had smaller adrenal glands than pups maintained in a standard homing cage $(50 \mathrm{~cm} \times 40 \mathrm{~cm} \times 20$ $\mathrm{cm}$ ) with only wood chips as bedding [71]. Also they found that pups reared in nests of newspaper had lower 
body temperatures than pups that had been reared in a standard maternity cage with no nest and the ability to thermo regulate is delayed in rats reared in a worm environment [72]. There is an enormous literature describing the effects of early handling on subsequent development of the pups including growth, emotionality, etc. Factors proposed as mediating the handling effect include increased tactile stimulation from the dam and exposure to a different thermal environment of the laboratory conditions. In other study showed a marked difference in the durations of inter-nest-bout-intervals (IBIS), between bouts of at least 10 min duration, warm-nesting dams show longer IBIS [73] [74].

\section{Ultrasonic Communication during Maternal Behavior}

Acoustic signals, such ultrasonic vocalizations (USV) which are characterized by frequencies between 30 and 80 $\mathrm{kHz}$ are detected by the mother and when this frequency are reproduce by artificial source it can be induce maternal behaviors [75]. Rodent pups emit USV when they are isolated from their mother and the incidence increase during first 6 - 7 days of life [76]. In previous studies mother were expose to odor pups or USV only additionally when both stimulus were present, the maternal behavior also increase when the odor and acoustic cues are present simultaneously, mother accepted and responded different cues of de pups simultaneously and each cue may facilitate maternal behavior [24].

\section{Reward Stimulus through Maternal Behavior}

Mother milk, is the only source of nutrients for the mammals neonate, mother also carries signals to the young in the form of neurotransmitters and hormones, which are essential for the neonate development. Because milk is so essential to the infant survival, it is not surprising that several learning paradigms based on milk reward has be successful developed for newborn and infant rats. One-day-old rats learn to press against an overhead paddle for milk recompense [77]. Rat pups are also capable of acquiring conditioned preferences for olfactory stimuli when these stimuli are associated with milk delivery [78] [79]. Intraoral milk infusions elicit specific responses associated with acquiring and ingesting nutrients, such as mouthing, probing, and behavioral activation in food-deprived infant rats [35] [80]. These specific appetitive responses can be elicited by an odor (conditioned stimulus, CS) subsequent to its classical pairing with and intraoral milk infusion (unconditioned stimulus, US) [81].

In rats the expression of food preferences is based on acquired experiences during the exposure of infant first to the mother's milk, her odor, then particles remaining around the mother mouth and on her fur and following the mother to the food place. More light discrimination by weaned animals of nutritious versus nutritionally deficient foods is based on learning [82]. The milk is also capable of initiating and sustaining suckling behavior in the newborn rat. Cesarean-delivered rat pups, tested 3 - 5 hr delivery and before any suckling experience, showed sustained attachment to and ingestion of milk from the surrogate nipple [83] [84]. Presentation of an empty surrogate nipple resulted in some components of appetitive behavior, including short oral grasping responses, but even continuous presentation of the empty nipple was not effective in eliciting sustained attachment [85]. Milk can reinforce components of early suckling behavior and establish the initial characteristics if behavioral responding to the nipple itself, transforming brief oral grasp responses to sustained nipple attachment. Changes in attachment to the empty nipple alone may serve as a behavioral assay for the reinforcing properties of milk in the first suckling episode. The milk reinforcing properties transform brief oral grasp responding into sustained attachment. In this case, milk can be considered as a primary reinforcing to the infant in the first nursing [86]. At the end of the second week of life of the pup rat the eyes and ear are open and have motor ability, the chemosensory systems have a sprouting in the different nuclei in route to the cortex. The pups have the opportunity to explore the niche and tray with the rest of pellet and remnant of mother poop, this transition period between the liquid food (milk) and solid food (pellet) is crucial for the establishment of taste learning.

\section{Intergenerational Influences}

Intergenerational effects been driven by efforts to understand the mechanisms underlying the abnormal by comparison to normal psychosocial development. In social primates, the importance of early mothering in determining how the daughters will mother is demonstrate under the conditions in which females offspring are partially or completely deprived of early mothering. For instance, rhesus monkeys can be rear with same aged peers rather than mothers (peer-reared monkeys). 
Plasticity in the maternal brain increases the reproductive fitness by allowing experience with one infant to modify the care of subsequent offspring in the changing environment in which the mother lives. Among many primate species, mothers of first infants are considerable less competent and motivated than are mothers of subsequent offspring in the changing environment and society, mothers of first infants are considerably less competent and motivated that are mothers of subsequent offspring. The experiences of the multiparous female are not limited to interactions with individual offspring. They include somatic and physiological experiences associated with pregnancy and parturition, as well as exposure to infants, peers, and larger environment and society, more generically. This effect of parity and the associated experiences usually insures that the young of an experienced.

For instance, infant rats who received more contact and licking stimulation from the mother in the nest show a higher level of pup licking as juveniles and as adults, when presented with newborn pups by comparisons to less stimulated infants. Moreover, other studies indicate that the quality of the infants nest experience also may well affect their later behavior [1] [3] [4] [8].

Maternal behavior in the first days following birth serves to platform the subsequent maternal behavior of the adult offspring as well as establishing the pups' levels of adrenal-pituitary-adrenal responsiveness to stress [85] [86]. Extreme forms of maternal deprivation have shown to have profoundly adverse effects on the development of maternal behavior. Early maternal stimulation in the nest also produces a decrease of the emotional reactivity of pups to novelty and stress when they become adults [87]. Reduction in stress reactivity are attributable in part to the increased density of hippocampal glucocorticoid receptors which normally mediate negative feedback effects of circulating adrenal glucocorticoids following hypothalamic-pituitary-adrenal (HPA) activation. Stimulation induces changes in thyroid function and serotonin system activity in the brain early in the postpartum period and involved in these long-term hippocampal effects [9].

The findings form cross-fostering studies deliver indication for an underlying relationship between maternal behavior and stress reactivity in the offspring and the transmission of individual differences from one generation of females to the next. The individual differences in the genetic expression in brain regions that regulate stress reactivity can be transmitted from parent to their progeny, advised that individual differences in behavioral fearfulness to novelty could be transmitted from parent to offspring through a no genomic mechanism of inheritance. Furthermore, environmental conditions imposed during early development alter maternal behavior in subsequent generations. Individual differences conduce to the variety of manner which mothers display the maternal behavior components such as attention, communication, avoid and others. The plasticity to stimulus respond such as vulnerability, positive or adverse early experience associated with the mother genetic package and determine the variability in the mother-pup bonding [88]. Studies for both in humans and in animal models shows that the nursing quality displayed to the daughter is transmitted to their descendants. It happens, in rats, maternal behaviors such as licking and grooming have been shown to be transmitted across generations [89] [90]. In human mothers, evidence exists for the intergenerational transmission of affective behaviors and nurturing styles [91]-[93]. In addition in humans fathers also deliver hostile experiences (socioeconomic, housing, parental status) that influence infants future behaviors [94]-[96].

\section{Human Maternal Behavior}

In human milk transfer can also be disrupted in the suckling behavior of the baby. The premature baby cannot suckle adequately and has to be feeding by stomach tube, preferably with the mother own milk must be breast milk obtained. Even in healthy babies, incorrect positioning on the breast, such that breathing is impaired, can disturb suckling behavior [97]. The survival and improved the human premature individual, when the suckling reflex is poorly developed, the use of pacifier accelerates the maturation of the sucking reflex. Nonnutritive sucking results in a more rapid weight gain, and change in the gastrointestinal motility and in the postnatal clinical course of these infants [97] [98]. Data support the concept that development of sucking activity is both an inborn conditioned reflex dependent primarily upon physiologic maturation. Sucking activity has a well-developed characteristic pattern in full-term infants. Deranged pattern of sucking utilized to identify infants with perinatal distress depression from obstetric anesthesia, or drug addiction in the mothers. Others findings support the concept that development of sucking is dependent upon both maturation and experience. Indeed sucking activity was noted to change in all infants from sporadic, slow sucking to more organized bursts of activity of gradually increasing suction pressure as postnatal age increased. The infants, who received daily nonnutritive opportuni- 
ties, developed this more organized sucking behavior earlier, a pattern that remained significantly different from that the control infants until the time at which nipple feeding became established. The initiation of bottle feedings in the control infants seemed to enhance the same parameters of sucking behavior that developed at an earlier age in the infants who received the nonnutritive opportunities during the gavages feedings.

The oral-facial muscular development alteration early on life influenced by genetic or epigenetic factors conduce to growing bone which when was altered produce malocclusion associated with oral habits practiced by a child. One of the important factors resulting in malocclusion is oral habit practiced by a child. Having an oral habit is not a tragic situation. Early in life dental developmental period, occurs troughs several steps until acquire healthy definitive teeth, any alteration interfere with the normal establishment of definitive bone, teeth and muscular structure [85] [97].

Benefits of findings from animal models model studies of an altered maternal behavior, during the lactating period may be relevant for the extrapolation of long-term behavioral disturbances in human maternal behavioral patterns, which are implicated in the normal development of the progeny. Also during perinatal period, brain of female mammals, show structural changes, associated to the repertoire of maternal behavior, milk production, for protect and ensure surviving of their progeny [99].

Also during perinatal period, brain of female mammals, show structural changes, associated to the repertoire of maternal behavior, milk production, for protect and ensure surviving of their progeny.

An interesting study related to the economic recession of 2008 shows the need to modify the rules of the child welfare and protection systems in Hungary and Romania. Evaluation analyses the social, political and economic aspects and the evolution of their child welfare systems. Special emphasis was placed on efforts to deinstitutionalize children from large institutions and develop local services to institutional care. Both countries have exemplary child protection legislation and policy based closely on the United Nations Convention for the Rights of the Child, family participation, and community involvement. Examples in both countries include the deinstitutionalization, creating modular group homes on the premises of old institutions thus generating improved statistics about closure of institutions with no change in actual everyday living conditions [100].

\section{Conclusions}

Findings in the current review show that mother-pup interactions are implicate in the survival of the progeny and the adjustment of the neuronal structures implicated. There is also need more data concerning which mother-pup interactions, mediators and biochemical pathways are responsible for environmental changes during mother-pup interaction. Although this topic is still only emergent, there are already a few interesting conclusions that can be drawn from existing data, because the biology of mother-pup interactions can elucidate data which conduce to the control of altered maternal behavior. In the human cases when the mother do not displays the adequate care to their progeny, this phenomenon can conduce to home accidents, psychological disorders, attention deficit and finely affects the optimal development. The differences between specie specific patterns elicited by psychogenic and physical development are result of the phylogenetic history, unified, and recognize the group of mammals. All of the studies comparing effects of different factors implicated in the maternal care on the environmental changes and the implicate brain areas.

Because the development of behavior patterns depend on physiological mechanisms followed by early experiences process for both mother and pup. The main roles of maternal cares has been studies in several small mammals and showed their role of body temperature control of the pup, being a crucial factor for the survival of the offspring. Implications of the mother-pup interaction represent a wide range of possibilities to conduce biological studies in order to suggest strategies of altered behavior consequences prevention in the human population. The knowledge of the developmental consequences of mother-young bonding and the essential mechanisms may help us to know psychiatric illnesses interrelated to child abuse, childhood carelessness or mother psychiatric deceases associated with negligence toward their sons.

\section{Perspectives}

The study of the mother-offspring relationships during lactation period distinctive of mammalians represents a great matter for the future research which should be conducting on multidisciplinary approach in order to understand the particular role of nursing and care quality, for benefits of psychosocial health of human populations. Finally, even for biological studies for comparisons across species and promote the collaborative strategies be- 
tween research groups, and improve our knowledge of the sociality that unified several species.

\section{Acknowledgements}

Author thanks the financial support by Fund for the Research Strengthening Autonomous University of Queretaro (FOFI-UAQ-2013) and thanks for Postdoctoral Fellow LRN (Exp 040962) to the National Council of Science and Technology (CONACyT). Author also thanks, for technical assistance to Enrique Ignacio Contla and to Gerardo Fonseca CFATA-UNAM.

\section{References}

[1] Kinsley, C.H. and Lambert, K.G. (2006) The Maternal Brain. Scientific American, 294, 72-79. http://dx.doi.org/10.1038/scientificamerican0106-72

[2] Fleming, A.S., O’Day, D.H. and Kraemer, G.W. (1999) Neurobiology of Mother-Infant Interactions: Experience and Central Nervous System Plasticity across Development and Generations. Neuroscience Biobehavioral Reviews, 23, 673-685. http://dx.doi.org/10.1016/S0149-7634(99)00011-1

[3] Van Hasselt, F.N., de Visser, L., Tieskens, J.M., Cornelisse, S., Baars, A.M., Lavrijsen, M., Kruger, H.J., Van Den Bos, R. and Joels, M. (2012) Individual Variations in Maternal Care Early in Life Correlate with Later Life Decision-Making a c-fos Expression in Prefrontal Subregions of Rats. PLoS One, 7, 1-11.

[4] Aguggia, J.P., Suárez, M.M. and Rivarola, M.A. (2013) Early Maternal Separation: Neurobehavioral Consequences. Behavioral Brain Research, 248, 25-31. http://dx.doi.org/10.1016/j.bbr.2013.03.040

[5] Stack, E.C., Balakrishnnan, X., Numan, M.J. and Numan, M. (2002) A Functional Neuroanatomical Investigation of the Role of the Medial Preoptic Area in Neural Circuits Regulating Maternal Behavior. Neuropsychopharmacology, 36, 2603-2615. http://dx.doi.org/10.1038/npp.2011.172

[6] Atzil, A., Hendler, T. and Feldman, R. (2011) Specifying the Neurobiological Basis of Human Attachment: Brain, Hormones, and Behavior in Synchronous and Intrusive Mothers. Neuropsychopharmacology, 36, 2603-2615. http://dx.doi.org/10.1038/npp.2011.172

[7] Pryce, C.R., Bettschen, D., Nanz-Bahr, N.I. and Feldon, J. (2003) Comparison of the Effects of Early Handling and Early Deprivation on Conditioned Stimulus, Context, and Spatial Learning and Memory in Adult Rats. Behavioral Neuroscience, 117, 883-893. http://dx.doi.org/10.1037/0735-7044.117.5.883

[8] Mogi, K., Nagasawa, M. and Kikusui, T. (2011) Developmental Consequences and Biological Significance of MotherInfant Bonding. Progress in Neuro-Psychopharmacology and Biological Psychiatry, 35, 1232-1241. http://dx.doi.org/10.1016/j.pnpbp.2010.08.024

[9] Kenny, S.L., Wright, L.D., Green, A.D., Mashoodh, R. and Perrot, T.S. (2013) Expression of Maternal Behavior and Activation of the Nucleus of the Bed Stria Terminalis during Predatory Threat Exposure: Modulatory Effects of Transport Stress. Physiology and Behavior, 1213, 148-155. http://dx.doi.org/10.1016/j.physbeh.2013.08.024

[10] Koletzko, B., Aggett, P.G., Bindels, J.G., Bung, P., Ferré, P., Gil, A., Lentze, M.J., Roberfroid, M. and Strobel, S. (1998) Growth, Development and Differentiation: A Functional Food Science Approach. British Journal of Nutrition, 80, S5-S45. http://dx.doi.org/10.1079/BJN19980104

[11] El-Fattah, A.M.A., Rabo, F.H.R.A., El-Dieb, S.M. and El-Kashef, H.A. (2012) Changes in Composition of Colostrum of Egyptian Buffaloes and Holstein Cows. Veterinary Research, 8, 1-7.

[12] Lis, J., Orczyk-Pawilowicz, M. and Katnik-Pratowska, I. (2013) Proteins of Human Milk Involved in Immunological Processes. Postepy Higieny i Medycyny Doswiadczalnej, 67, 529-547. http://dx.doi.org/10.5604/17322693.1051648

[13] Mayer, A.D. and Rosenblatt, J.S. (1993) Hormonal Factors Influence the Onset of Maternal Aggression in Laboratory Rats. Hormones and Behavior, 21, 253-267. http://dx.doi.org/10.1016/0018-506X(87)90050-X

[14] Curley, J.P., Jordan, E., Swaney, W.T., Izraelit, A., Kammel, S. and Champagne, F.A. (2009) The Meaning of Weaning: Influence of the Weaning Period on Behavioral Development in Mice. Developmental Neuroscience, 31, 318-331. http://dx.doi.org/10.1159/000216543

[15] Shahrokh, D.K., Zhang, T.Y., Diorio, J., Gratton, A. and Meaney, M.J. (2010) Oxytocin-Dopamine Interactions Mediate Variations in Maternal Behavior in the Rat. Endocrinology, 151, 2276-2286. http://dx.doi.org/10.1210/en.2009-1271

[16] Barrett, J. and Fleming, A.S. (2011) All Mothers Are Not Created Equal: Neural and Psychobiological Perspectives on Mothering and the Importance of Individual Differences. Journal of Child Psychology and Psychiatry, 52, 368-397. http://dx.doi.org/10.1111/j.1469-7610.2010.02306.x

[17] Numan, M. (1994) A Neural Circuitry Analysis of Maternal Behavior in the Rat. Acta Paediatrica, 397, 19-28. 
http://dx.doi.org/10.1111/j.1651-2227.1994.tb13261.x

[18] Numan, M. and Numan, M.J. (1994) Expression of Fos-Like Immunoreactivity in the Preoptic Area of Maternally Behaving Virgin and Postpartum Rats. Behavioral Neuroscience, 108, 379-394. http://dx.doi.org/10.1037/0735-7044.108.2.379

[19] Numan, M. and Sheehan, T.P. (1997) Neuroanatomical Circuitry for Mammalian Maternal Behavior. Annals of the New York Academy of Sciences, 807, 101-125. http://dx.doi.org/10.1111/j.1749-6632.1997.tb51915.x

[20] Sheehan, T.P., Cirrito, J., Numan, M.J. and Numan, M. (2000) Using c-Fos Immunocytochemistry to Identify Forebrain Regions That May Inhibit Maternal Behavior in Rats. Behavioral Neuroscience, 114, 337-352. http://dx.doi.org/10.1037/0735-7044.114.2.337

[21] Wood, R.I. and Swann, J.M. (2005) The Bed Nucleus of the Stria Terminalis in the Syrian Hamster: Subnuclei and Connections of the Posterior Division. Neuroscience, 135, 155-179. http://dx.doi.org/10.1016/j.neuroscience.2005.05.029

[22] Douglas, A.J. (2010) Baby Love? Oxytocin-Dopamine Interactions in Mother-Infant Bonding. Endocrinology, 151, 1978-1980. http://dx.doi.org/10.1210/en.2010-0259

[23] Stern, J.M. (1997) Trigeminal Lesions and Maternal Behaviors in Norway Rats: III. Experience with Pups Facilitates Recovery. Developmental Psychobiology, 30, 115-126. http://dx.doi.org/10.1002/(SICI)1098-2302(199703)30:2<115::AID-DEV3>3.0.CO;2-T

[24] Okabe, S., Nagasawa, M., Kato, M., Koshida, N., Kihara, T., Harada, T., Mogi, K. and Kikusui, T. (2013) Pup Odor and Ultrasonic Vocalization Synergistically Stimulate Maternal Attention in Mice. Behavioral Neuroscience, 127, 432438. http://dx.doi.org/10.1037/a0032395

[25] Nagasawa, M., Okabe, S., Mogi, K. and Kikusui, T. (2012) Oxytocin and Mutual Communication in Mother-Infant Bonding. Frontiers in Human Neuroscience, 28, 1-10.

[26] Fleming, A.S., Vaccarino, F. and Luebke, C. (1980) Amygdaloid Inhibition of Maternal Behavior in the Nulliparous Female Rat. Physiology and Behavior, 25, 731-743. http://dx.doi.org/10.1016/0031-9384(80)90377-7

[27] Francis, D.D., Champagne, F.C. and Meany, M.J. (2000) Variations in Maternal Behaviors Are Associated with Differences in Oxytocin Receptors Levels in the Rat. Journal of Neuroendocrinology, 12, 1145-1148. http://dx.doi.org/10.1046/j.1365-2826.2000.00599.x

[28] Kendrick, K.M. (2000) Oxitocin, Motherhood and Bonding. Experimental Physiology, 85, 111S-124S. http://dx.doi.org/10.1111/j.1469-445X.2000.tb00014.X

[29] Levine, A., Zagoory-Sharon, O., Feldman, R. and Weller, A. (2007) Oxytocin during Pregnancy and Early Postpartum: Individual Patterns and Maternal-Fetal Attachment. Peptides, 28, 1162-1169. http://dx.doi.org/10.1016/j.peptides.2007.04.016

[30] Sullivan, R. (2006) Developing a Sense of Safety. The Neurobiology of Neonatal Attachment. Annals of the New York Academy of Sciences, 1008, 122-131. http://dx.doi.org/10.1196/annals.1301.013

[31] Knobil, E. and Neil, J. (1998) Encyclopedia of Reproduction. Academic Press, Waltham.

[32] Fleming, A.S. and Rosenblatt, J.S. (1974) Maternal Behavior in the Virgin and Lactating Rat. The Journal of Comparative and Physiological Psychology, 86, 957-972. http://dx.doi.org/10.1037/h0036414

[33] Yu, G.Z., Kaba, H., Okutani, F., Takahashi, S. and Higuchi, T. (1996) The Olfactory Bulb: A Critical Site of Action for Oxytocin in the Induction of Maternal Behaviour in the Rat. Neuroscience, 72, 1083-1088. http://dx.doi.org/10.1016/0306-4522(95)00600-1

[34] Hall, W.G. (1975) Weaning and Growth of Artificially Reared Rats. Science, 190, 1313-1315. http://dx.doi.org/10.1126/science.1198116

[35] Hall, W.G. (1979) Feeding and Behavioral Activation in Infant Rats. Science, 205, 206-209. http://dx.doi.org/10.1126/science.451591

[36] Williams, C.L., Rosenblat, J.S. and Hall, W.G. (1979) Inhibition of Suckling in Weaning Age Rats: A Possible Serotonergic Mechanism. Journal of Comparative and Physiological Psychology, 93, 414-429. http://dx.doi.org/10.1037/h0077592

[37] Kenny, J.T., Stoloff, M.L., Bruno, J.P. and Blass, E.M. (1979) Ontogeny of Preference for Nutritive over Nonnutritive Suckling in Albino Rats. Journal of Comparative and Physiological Psychology, 93, 752-759. http://dx.doi.org/10.1037/h0077598

[38] Thiels, C. (1987) Pharmacotherapy of Psychiatric Disorder in Pregnancy and during Breastfeeding: A Review. Pharmacopsychiatry, 20, 133-146. http://dx.doi.org/10.1055/s-2007-1017092

[39] Stoloff, M.L. and Blass, E.M. (1983) Changes in Appetitive Behavior in Weanling-Age Rats: Transitions from Suckling to Feeding Behavior. Developmental Psychobiology, 16, 439-453. http://dx.doi.org/10.1002/dev.420160508 
[40] Pfister, H.P. and Muir, J.L. (1989) Psychological Stress and Administers Oxytocin during Pregnancy: Effect Corticosterone and Prolactin Response in Lactating Rats. International Journal of Neuroscience, 45, 91-99. http://dx.doi.org/10.3109/00207458908986220

[41] Lavi-Avnon, Y., Yadid, G., Overstreet, D.H. and Weller, A. (2005) Abnormal Patterns of Maternal Behavior in a Genetic Animal Model of Depression. Physiology and Behavior, 84, 607-615. http://dx.doi.org/10.1016/j.physbeh.2005.02.006

[42] Lichtman, A.H. and Cramer, C.P. (1989) Relative Importance of Experience, Social Facilitation, and Availability of Milk in Weaning of Rats. Developmental and Psychobiology, 22, 347-356. http://dx.doi.org/10.1002/dev.420220403

[43] Berridge, K.C. (2000) Measuring Hedonic Impact in Animal and Infant: Microstructure of Affective Taste Reactivity Patterns. Neuroscience and Biobehavioral Reviews, 24, 173-198. http://dx.doi.org/10.1016/S0149-7634(99)00072-X

[44] Jaffrey, S.R. and Snyder, S.H. (1995) Nitric Oxide: A Neural Messenger. Annual Review of Cell and Developmental Biology, 1, 417-440. http://dx.doi.org/10.1146/annurev.cb.11.110195.002221

[45] Huang, P.L., Dawson, T.M., Bredt, D.S., Snyde, S.H. and Fishman, M.C. (1993) Targeted Disruption of the Neuronal Nitric Oxide Synthase Gene. Cell, 75, 1273-1286. http://dx.doi.org/10.1016/0092-8674(93)90615-W

[46] Demas, G.E., Mikael, J.L., Eliasson, T.M., Dawson, V.L., Dawson, L.J., Randy, J., Nelson, R.J. and Snyder, SH. (1997) Inhibition of Neuronal Nitric Oxide Synthase Increases Aggressive Behavior in Mice. Molecular Medicine, 3, 610-616.

[47] Butter, A. and Nicholson, R. (2003) Life, Death and Nitric Oxide. Chapter 15, No in Nerves. Royal Society of Chemistry, Cambridge, 115-125.

[48] Okere, C.O., Higuchi, T., Kaba, H., Russell, J.A., Okutani, F., Takahashi, S. and Murata, T. (1996) Nitric Oxide Prolongs Parturition and Inhibits Maternal Behavior in Rats. Neuroreport, 7, 1695-1699. http://dx.doi.org/10.1097/00001756-199607080-00034

[49] Kendrick, K.M., Guervara-Guzman, R., Zorrilla, J., Hinton, M.R., Broad, K.D., Mimmack, M. and Ohkura, S. (1997) Formation of Olfactory Memories Mediates by Nitric Oxide. Nature, 388, 670-674. http://dx.doi.org/10.1038/41765

[50] Gammie, S.C. and Nelson, R.J. (2000) Maternal and Mating-Induce Aggression in Associated with Elevate Citrulline Immunoreactivity in the Paraventricular Nucleus in Prairie Voles. Journal of Comparative Neurology, 418, 182-192. http://dx.doi.org/10.1002/(SICI)1096-9861(20000306)418:2<182::AID-CNE5>3.0.CO;2-1

[51] Stern, J.M. and Lonstein, J.S. (1996) Nursing Behavior in Rats is Impaired in a Small Nestbox and with Hyperthermic Pups. Developmental Psychobiology, 29, 101-122. http://dx.doi.org/10.1002/(SICI)1098-2302(199603)29:2<101::AID-DEV2>3.0.CO;2-W

[52] Pedersen, P.E. and Blass, E.M. (1982) Prenatal and Postnatal Determinants of the 1st Suckling Episode in Albino Rats. Developmental Psychobiology, 15, 349-355. http://dx.doi.org/10.1002/dev.420150407

[53] Wilson, D.A. and Sullivan, R.M. (1994) Neurobiology of Associative Learning in the Neonate: Early Olfactory Learning. Behavioral and Neural Biology, 61, 1-18. http://dx.doi.org/10.1016/S0163-1047(05)80039-1

[54] Rosenblatt, J.S. (1967) Nonhormonal Basis of Maternal Behavior in the Rat. Science, 156, 1512-1514. http://dx.doi.org/10.1126/science.156.3781.1512

[55] Fleming, A.S., Cheung, U., Myhal, N. and Kessler, Z. (1989) Effects of Maternal Hormones on “Timidity” and Attraction to Pup-Related Odors in Female Rats. Physiology and Behavior, 46, 449-453. http://dx.doi.org/10.1016/0031-9384(89)90019-X

[56] Rosenblatt, J.S. (1971) Suckling and Home Orientation in the Kitten: A Comparative Developmental Study. In: Tobach, E., Aronson, L. and Shaw, E., Eds., The Biopsychology of Development, Academic Press, New York, 345-410.

[57] Myers, K.P. and Sclafani, A. (2006) Development of Learned Flavor Preferences. Developmental Psychobiology, 48, 380-388. http://dx.doi.org/10.1002/dev.20147

[58] Champagne, F.A. (2013) Early Environments, Glucocorticoid Receptors, and Behavioral Epigenetics. Behavioral Neuroscience, 127, 628-636. http://dx.doi.org/10.1037/a0034186

[59] Eklund, M.B., Johansson, L.M., Uvnäs-Moberg, K. and Arborelius, L. (2009) Differential Effects of Repeated Long and Brief Maternal Separation on Behaviour and Neuroendocrine Parameters in Wistar Dams. Behavioural Brain Research, 203, 69-75. http://dx.doi.org/10.1016/j.bbr.2009.04.017

[60] Orpen, B.G. and Fleming, A.S. (1987) Experience with Pups Sustains Maternal Responding in Postpartum Rats. Physiology and Behavior, 40, 47-54. http://dx.doi.org/10.1016/0031-9384(87)90184-3

[61] Stankiewicz, A.D., Swiergiel, A.H. and Lisowski, P. (2013) Epigenetics of Stress Adaptation in the Brain. Brain Research Bulletin, 98, 76-92. http://dx.doi.org/10.1016/j.brainresbull.2013.07.003

[62] Woodside, B. and Leon, M. (1980) Thermoendocrine Influences on Maternal Nesting Behavior in Rats. Journal of Comparative and Physiological Psychology, 94, 41-60. http://dx.doi.org/10.1037/h0077652 
[63] Jans, J.E. and Leon, M. (1983) The Effects of Lactation and Ambient Temperature on the Body Temperature of Female Norway Rats. Physiology and Behavior, 30, 959-961. http://dx.doi.org/10.1016/0031-9384(83)90261-5

[64] Denenberg, V.H., Taylor, R.E. and Zarrow, M.X. (1968) Maternal Behavior in the Rat: An Investigation and Quantification of Nest Building. Behaviour, 34, 1-16. http://dx.doi.org/10.1163/156853969X00369

[65] Jans, J.E. and Woodside, B. (1987) Effects of Litter Age, Litter Size, and Ambient Temperature on the Milk Ejection Reflex in Lactating Rats. Developmental Psychobiology, 20, 333-344. http://dx.doi.org/10.1002/dev.420200310

[66] Jans, J.E., de Villers, S. and Woodside, B. (1985) The Effects of Rearing Environment on Pup Development. Developmental Psychobiology, 18, 341-347. http://dx.doi.org/10.1002/dev.420180406

[67] Daly, M. (1973) Early Stimulation of Rodents: A Critical Review of Present Interpretations. British Journal of Psychology, 64, 435-460. http://dx.doi.org/10.1111/j.2044-8295.1973.tb01370.x

[68] Kuhn, C.M. and Schanberg, S.M. (1988) Responses to Maternal Separation: Mechanisms and Mediators. International Journal of Developmental Neuroscience, 16, 261-270. http://dx.doi.org/10.1016/S0736-5748(98)00034-3

[69] Seffer, D., Schwarting, R.K. and Wohr, M. (2014) Pro-Social Ultrasonic Communication in Rats: Insights from Play Back Studies. The Journal of Neuroscience Methods, 234, 73-81. http://dx.doi.org/10.1016/j.jneumeth.2014.01.023

[70] Ehret, G. (2005) Infant Rodent Ultrasounds a Gate to the Understanding of Sound Communication. Behavior Genetics, 35, 19-29. http://dx.doi.org/10.1007/s10519-004-0853-8

[71] Johanson, I.B. and Hall, W.G. (1979) Appetitive Learning in 1-Day-Old Rat Pups. Science, 205, 419-421. http://dx.doi.org/10.1126/science.451612

[72] Johanson, I.B. and Teicher, M.H. (1980) Classical Conditioning of an Odor Preference in 3-Day-Old Rats. Behavioral and Neural Biology, 29, 132-136. http://dx.doi.org/10.1016/S0163-1047(80)92596-0

[73] Brake, S.C. (1981) Suckling Infant Rats Learn a Preference for a Novel Olfactory Stimulus Paired with Milk Delivery. Science, 211, 506-508. http://dx.doi.org/10.1126/science.7192882

[74] Johanson, I.B. and Hall, W.G. (1982) Appetitive Conditioning in Neonatal Rats: Conditioned Orientation to a Novel Odor. Developmental Psychobiology, 15, 379-397. http://dx.doi.org/10.1002/dev.420150410

[75] Hall, W.G. and Rosenblatt, J.S. (1979) Developmental Changes in the Suckling Behavior of Hamster Pups: A Comparison with Rat Pups. Developmental Psychobiology, 12, 553-560. http://dx.doi.org/10.1002/dev.420120605

[76] Johanson, I.B., Hall, W.G. and Polefrone, J.M. (1984) Appetitive Conditioning in Neonatal Rats: Conditioned Ingestive Responding to Stimuli Paired with Oral Infusions of Milk. Developmental Psychobiology, 17, 357-381. http://dx.doi.org/10.1002/dev.420170404

[77] Malenfant, S.A., Barry, M. and Fleming, A.S. (1991) Effects of Cycloheximide on the Retention of Olfactory Learning and Maternal Experience Effects in Postpartum Rats. Physiology and Behavior, 49, 289-294. http://dx.doi.org/10.1016/0031-9384(91)90045-P

[78] Petrov, E.S., Varlinskaya, E.I. and Smotherman, W.P. (1997) The Newborn Rat Ingests Fluids through a Surrogate Nipple: A New Technique for the Study of Early Suckling Behavior. Physiology and Behavior, 62, 1155-1158.

[79] Petrov, E.S., Varlinskaya, E.I., Bregman, K. and Smotherman, W.P. (1999) Sustained Attachment to the Nipple in the Newborn Rat Depends on Experience with the Nipple, Milk, and the Expression of Oral Grasping. Behavioral Neuroscience, 113, 211-221. http://dx.doi.org/10.1037/0735-7044.113.1.211

[80] Smotherman, W.P., Petrov, E.S. and Varlinskaya, E.I. (1997) Experimental Study of the First Suckling Episode: Rat Pups Ingest Fluids through a Surrogate Nipple. Behavioral Neuroscience, 111, 1383-1394. http://dx.doi.org/10.1037/0735-7044.111.6.1383

[81] Cheslock, S.J., Varlinskaya, E.I., Petrov, E.S. and Spear, N.E. (2000) Rapid and Robust Olfactory Conditioning with Milk before Suckling Experience: Promotion of Nipple Attachment in The Newborn Rat. Behavioral Neuroscience, 114, 484-495. http://dx.doi.org/10.1037/0735-7044.114.3.484

[82] Levine, J.H., Nicholson, W.E., Pwytremann, A. and Orth, D.N. (1975) The Mechanism of ACTH Stimulation of Adrenal Ornithine Decarboxylase Activity. Endocrinology, 97, 136-144. http://dx.doi.org/10.1210/endo-97-1-136

[83] Francis, D.D. and Meaney, M.J. (1999) Maternal Care and the Development of Stress Responses. Current Opinion in Neurobiology, 9, 128-134. http://dx.doi.org/10.1016/S0959-4388(99)80016-6

[84] Liu, L., Li, A. and Matthews, S.G. (2001) Maternal Glucocorticoid Treatment Programs HPA Regulation in Adult Offspring: Sex Specific Effects. American Journal of Physiology Endocrinology and Metabolism, 280, E729-E739.

[85] Francis, D., Diorio, J., Liu, D. and Meaney, M.J. (1999) Nongenomic Transmission across Generations of Maternal Behavior and Stress Responses in the Rat. Science, 286, 1155-1158. http://dx.doi.org/10.1126/science.286.5442.1155

[86] Salas, M., Torrero, C., Regalado, M. and Perez, E. (2002) Retrieving of Pups by Neonatally Stressed Mothers. Nutritional Neuroscience, 5, 399-405. http://dx.doi.org/10.1080/1028415021000055943 
[87] Perez-Torrero, E. and Salas, M. (2007) Early Undernourishment Interferes with the Maternal Aggressive Response Triggered by an Intruder Entering the Homing Cage. Nutritional Neuroscience, 10, 17-22. http://dx.doi.org/10.1080/10284150601165110

[88] Barrett, J. and Fleming, A.S. (2011) Annual Research Review: All Mothers Are Not Created Equal: Neural and Psychobiological Perspectives on Mothering and the Importance of Individual Differences. Journal of Child Psychology and Psychiatry, 52, 368-397. http://dx.doi.org/10.1111/j.1469-7610.2010.02306.x

[89] Fleming, A.S., Kraemer, G.W., Gonzalez, A., Lovic, V., Rees, S. and Melo, A. (2002) Mothering Begets Mothering: The Transmission of Behavior and Its Neurobiology across Generations. Pharmacology, Biochemistry and Behavior, 73, 61-75. http://dx.doi.org/10.1016/S0091-3057(02)00793-1

[90] Numan, M., Fleming, A.S. and Levy, F. (2006) Maternal Behavior. In: Knobil, J.D. and Neill, N., Eds., Physiology of Reproduction, Academic Press, New York, 1921-1993.

[91] Wickramaratne, P.J. and Weissman, M.M. (1998) Onset of Psychopathology in Offspring by Developmental Phase and Parental Depression. Journal of the American Academy of Child and Adolescent Psychiatry, 37, 933-942. http://dx.doi.org/10.1097/00004583-199809000-00013

[92] Weissman, M. (2006) Recent Advances in Depression across the Generations. Epidemiologia e Psichiatria Sociale, 15, 16-19.

[93] Champagne, F. and Meaney, M.J. (2001) Like Mother, Like Daughter: Evidence for Non-Genomic Transmission of Parental Behavior and Stress Responsivity. Progress in Brain Research, 133, 287-302. http://dx.doi.org/10.1016/S0079-6123(01)33022-4

[94] Levitan, R.D., Rector, N.A., Sheldon, T. and Goering, P. (2003) Childhood Adversities Associated with Major Depression and/or Anxiety Disorders in a Community Sample of Ontario: Issues of Co-Morbidity and Specificity. Depression and Anxiety, 17, 34-42. http://dx.doi.org/10.1002/da.10077

[95] Rikhye, K., Tyrka, A.R., Kelly, M.M., Gagne, G.G., Mello, A.F., Mello, M.F., Price, L.H. and Carpenter, L.L. (2008) Interplay between Childhood Maltreatment, Parental Bonding, and Gender Effects: Impact on Quality of Life. Child Abuse and Neglect, 32, 19-34. http://dx.doi.org/10.1016/j.chiabu.2007.04.012

[96] Klein, D.N., Arnow, B.A., Barkin, J.L., Dowling, F., Kocsis, J.H., Leon, A.C, Manber, R., Rothbaum, B.O., Trivedi, M.H. and Wisniewski, S.R. (2009) Early Adversity in Chronic Depression: Clinical Correlates and Response to Pharmacotherapy. Depression and Anxiety, 26, 701-710. http://dx.doi.org/10.1002/da.20577

[97] Franco Varas, V. and Gorritxo Gil, B. (2012) Pacifier Sucking Habit and Associated Dental Changes. Importance of Early Diagnosis. Anales de Pediatría, 77, 374-380. http://dx.doi.org/10.1016/j.anpedi.2012.02.020

[98] Jyoti, S. and Pavanalakshmi, G.P. (2014) Nutritive and Non-Nutritive Sucking Habits-Effect on the Developing OroFacial Complex: A Review. Dentistry, 4, 203-206.

[99] Howard, C.H. and Kelly, G.L. (2006) The Maternal Brain. Scientific American, 294, 72-79. http://dx.doi.org/10.1038/scientificamerican0106-72

[100] Anghela, R., Herczogb, M. and Dimac, G. (2013) The Challenge of Reforming Child Protection in Eastern Europe: The Cases of Hungary and Romania. Psychosocial Intervention, 22, 239-249. http://dx.doi.org/10.5093/in2013a27 
Scientific Research Publishing (SCIRP) is one of the largest Open Access journal publishers. It is currently publishing more than 200 open access, online, peer-reviewed journals covering a wide range of academic disciplines. SCIRP serves the worldwide academic communities and contributes to the progress and application of science with its publication.

Other selected journals from SCIRP are listed as below. Submit your manuscript to us via either submit@scirp.org or Online Submission Portal.
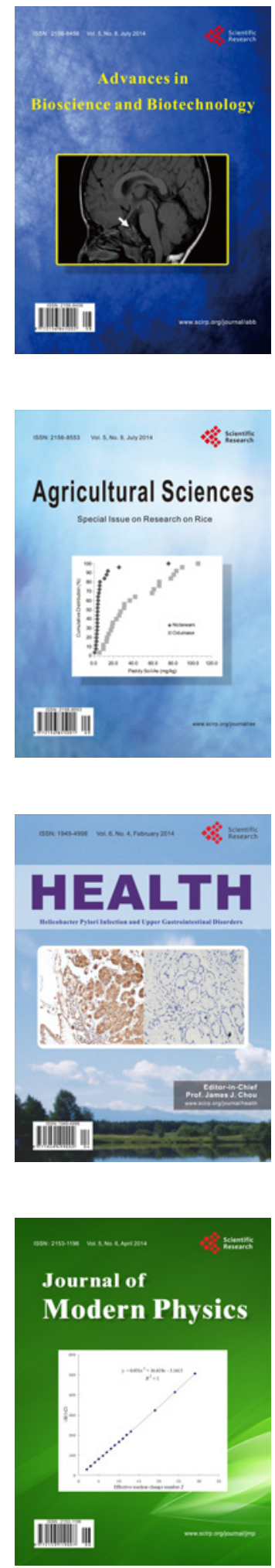
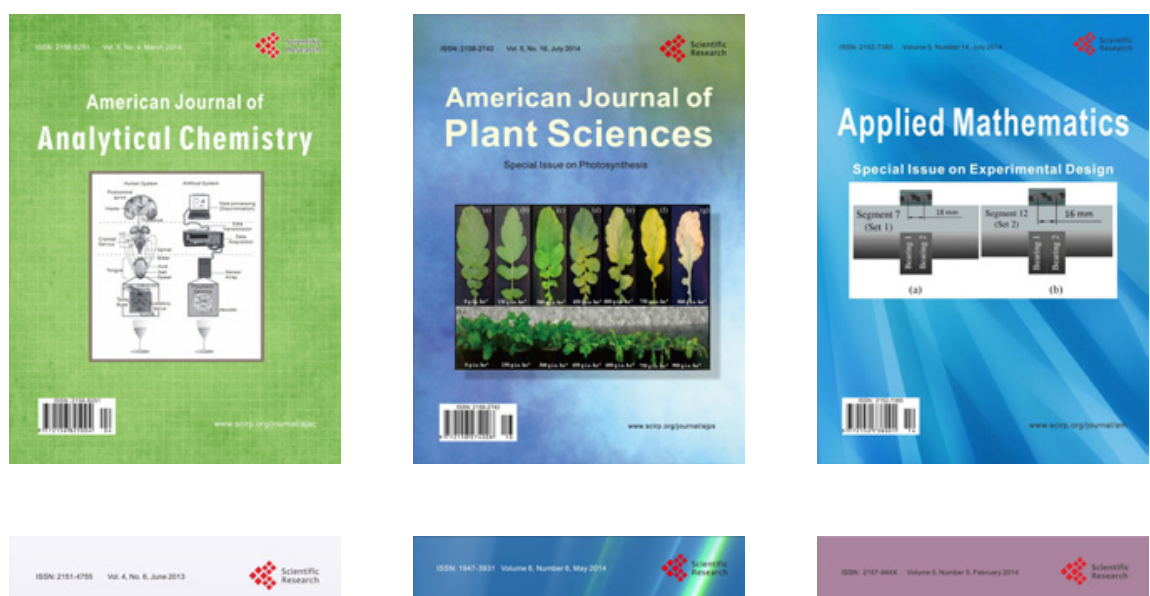

Creative Education
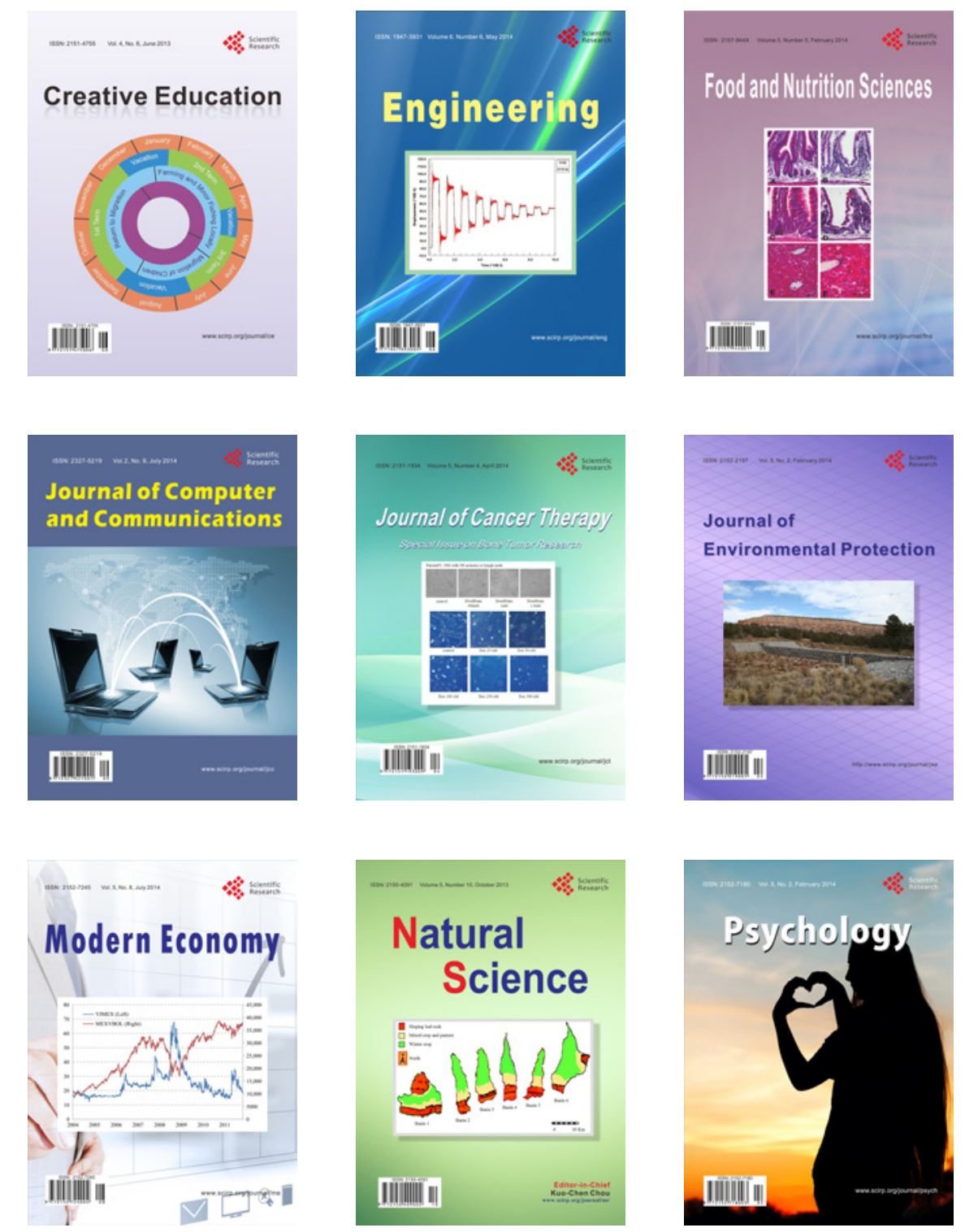